\title{
TEORIA HISTÓRICO-CULTURAL E ENSINO DE MATEMÁTICA: LEVANTAMENTO DOS TRABALHOS APRESENTADOS NO XI ENCONTRO NACIONAL DE EDUCAÇÃO MATEMÁTICA (ENEM)
}

\author{
Elizabeth de Lourdes Primo Cotrim, Thaís de Sá Gomes Novaes
}

Universidade Estadual do Norte do Paraná - UENP, Colegiado de Pedagogia, Cornélio Procópio, PR. E-mail: thaisdesa@bs2.com.br

\section{RESUMO}

O objetivo do trabalho consistiu em investigar as pesquisas sobre a Teoria Histórico-Cultural e o ensino de Matemática nos anais do XI Encontro Nacional de Educação Matemática (ENEM), realizado no ano de 2013. Trata-se de uma pesquisa qualitativa que segue o delineamento de um levantamento. Os termos dos títulos e as palavras-chaves empregadas pelos autores nem sempre são muito expressivas das temáticas abordadas nas escritas, que só foi possível de ser identificada com a leitura integral dos resumos. Dentre os conceitos da Teoria Histórico-Cultural abordados nas produções analisadas, destacaram-se: aprendizagem, significado e desenvolvimento. Os resultados obtidos com a pesquisa podem subsidiar novos estudos sobre o ensino da matemática fundamentados na Teoria Histórico-Cultural.

Palavras-chave: Teoria Histórico-Cultural, Ensino de Matemática, Encontro Nacional de Educação Matemática (ENEM).

\section{HISTORICAL-CULTURAL THEORY AND MATHEMATICS TEACHING: SURVEY OF THE WORKS PRESENTED AT XI NATIONAL MEETING OF MATHEMATICAL EDUCATION (ENEM)}

\footnotetext{
ABSTRACT

The objective of the work consisted in investigating the research on the Historical-Cultural Theory and the teaching of Mathematics in the annals of the XI National Meeting of Education Mathematics (ENEM), held in the year 2013. It is a qualitative research that follows the design of a withdrawal. The terms of the titles and key words appointed by the authors are not always very expressive of the themes covered in the writings, which was only possible to be identified with the full reading of the abstract. Among the concepts of the Historical-Cultural Theory studied in the analyzed production, they highlighted: learning, meaning and development. The results obtained with the research can subsidize new studies on the teaching of Mathematics based on HistoricalCultural Theory.

Keywords: Historical-Cultural Theory, Mathematics Teaching, National Meeting of Mathematics Education (ENEM).
} 


\section{INTRODUÇÃO}

Refletir sobre a organização do ensino de Matemática, buscando compreender os encaminhamentos teórico-metodológicos que envolvem o ensino desse campo do saber possibilita contribuir para o enriquecimento da prática pedagógica dos professores, especialmente, daqueles que atuam na educação básica. No entanto, o enriquecimento da prática pedagógica não se resume a atualização de atividades ou aquisição de um receituário metodológico a ser seguido na sala de aula, mas a um profundo processo de reorganização do ensino de acordo com a finalidade primeira da escola: o ensino dos conteúdos científicos, filosóficos e artísticos.

É possível inferir que os pressupostos da Teoria Histórico-Cultural constituem-se em importante referência para a compreensão e qualificação do ensino escolar atual, no sentido de que o trabalho pedagógico, ancorado em seus fundamentos, possibilita a apropriação dos conhecimentos produzidos pela humanidade, potencializando o desenvolvimento dos sujeitos envolvidos no processo educativo.

Para o homem encarnar o desenvolvimento da espécie humana, é necessário apropriar-se dos bens culturais, ou seja, como afirma Saviani (1985, p. 80), do "próprio modo como é produzida a existência humana". Às produções sócio-históricas do gênero humano, que garantem e facilitam sua vida, entre elas os instrumentos, as técnicas e as ideias, é dado o nome de cultura.

Neste sentido, a escola é considerada o espaço por excelência de disseminação e apropriação dos conhecimentos científicos, uma vez que é a instituição capaz de fazer a mediação entre os conceitos cotidianos e os científicos. Nas palavras de Saviani (1991, p. 29): "Em suma, pela mediação da escola, dá-se a passagem do saber espontâneo ao saber sistematizado, da cultura popular à cultura erudita".

Para a disciplina de Matemática, as contribuições da Teoria Histórico-Cultural podem auxiliar na organização do seu ensino, de modo que os conteúdos sejam trabalhados no sentido de promover a apropriação dos conceitos matemáticos pelos escolares, e não somente a memorização e repetição de símbolos e algoritmos. Nas palavras de Vigotski ${ }^{1}$ (1998, p. 118), “o aprendizado adequadamente organizado resulta em desenvolvimento mental e põe em movimento vários processos de desenvolvimento que, de outra forma, seriam impossíveis de acontecer".

Assim sendo, o objetivo deste trabalho consistiu em identificar os trabalhos disponibilizados, no subeixo "A Educação Matemática Sob o Enfoque Histórico-cultural”, presentes no eixo 2 "Pesquisa em Educação Matemática" do XI ENEM - Encontro Nacional de Educação Matemática no ano de 2013; a fim de organizar um panorama dos estudos, além de constituir um banco de dados para acesso, organização e pesquisa do material para subsidiar novos estudos sobre a temática.

\section{METODOLOGIA}

Esse estudo trata-se de uma pesquisa qualitativa (BOGDAN; BIKLEN, 1994; GIL, 2010) que segue o delineamento de um levantamento. Essa modalidade de pesquisa configura-se como um estudo bibliográfico inventariante, que se debruça sobre um corpus de análise definido a fim de destacar o que as pesquisas de determinada área trazem em comum. Portanto, as pesquisas de levantamento objetivam mapear e descrever certas produções acadêmicas em distintos campos do conhecimento, tentando responder que aspectos e dimensões são privilegiados em diferentes épocas e lugares.

Para fins de circunscrever um campo de análise de nosso estudo tomamos por referência os anais do Encontro Nacional de Educação Matemática (ENEM). O corpus de análise considerado

\footnotetext{
${ }^{1}$ Ao utilizar a grafia do nome do autor russo Lev Semenovich Vigotski no corpo do texto optou-se pela escrita Vigotski. Mas, nas referências bibliográficas será mantida a grafia da obra original.
} 
justificou-se por ser o evento brasileiro mais importante da área de Educação Matemática e a escolha do recorte temporal no XI ENEM, que aconteceu no ano de 2013, quando o evento representou a comemoração dos 25 anos da criação da Sociedade Brasileira de Educação Matemática - SBEM e inaugurou um subeixo intitulado "A Educação matemática sob o enfoque histórico-cultural", presente no eixo "Pesquisa em Educação Matemática". Portanto, o critério utilizado para a seleção consistiu em incluir apenas os trabalhos que se encontravam nesse subeixo.

O primeiro momento da pesquisa constituiu-se no estudo bibliográfico de alguns conceitos da Teoria Histórico-Cultural e Educação Matemática, posteriormente, foi realizada seleção das fontes de investigação disponibilizadas nos anais do XI Encontro Nacional de Educação Matemática (ENEM), por meio do endereço eletrônico http://sbem.esquiro.kinghost.net/anais/XIENEM/trabalhos_1.html.

$\mathrm{Na}$ primeira consulta aos anais do evento, notamos que os trabalhos não estavam organizados e disponíveis separadamente por cada eixo e subeixo. Desse modo, foi necessário realizar uma busca no menu autores, no qual consta o nome dos autores de todos os trabalhos do evento, o título, a área temática e também o arquivo em extensão PDF².

Nesta busca inicial foram encontrados 312 trabalhos classificados como sendo do eixo dois, denominado "Pesquisa em Educação Matemática". No entanto, esse eixo era composto por nove (09) subeixos e tal classificação não foi identificada e descrita pela organização do evento. Desse modo, fez-se necessário realizar a leitura dos títulos e palavras-chave e, posteriormente a leitura integral dos resumos de todos os trabalhos do eixo, para identificar os trabalhos que poderiam pertencer ao subeixo "A Educação matemática sob o enfoque histórico-cultural". Os critérios utilizados para a realização dessa classificação foram:

- descrição, no resumo, da fundamentação teórica utilizada no trabalho, como por exemplo, abordagem construtivista, modelagem matemática, educação matemática crítica, Teoria Histórico-cultural, entre outras.

- citação dos teóricos utilizados pelos autores dos textos, como Piaget, Skovsmose, Vygotsky, Leontiev, Davydov, entre outros;

- apresentação de conceitos que poderiam fazer referência aos princípios teóricos da Teoria Histórico-cultural, como (linguagem, aprendizagem, desenvolvimento, Zona de Desenvolvimento Próximo, mediação entre outros);

- citação de pesquisadores da área de Educação Matemática que se fundamentam na Teoria Histórico-cultural - identificados na primeira etapa da pesquisa - como Moura, Moraes, Araújo, Moretti, Pannossian, etc.

Dos 312 trabalhos do eixo dois, classificamos 46 trabalhos como sendo do subeixo "A Educação matemática sob o enfoque histórico-cultural", de interesse desta pesquisa, nos quais foram categorizados em um quadro, quanto à temática, conceitos da teoria abordados, tipo de pesquisa e produção acadêmica por região do país, por meio da instituição a qual pertence o(s) autor(s).

\section{RESULTADOS E DISCUSSÃO}

Quanto à análise dos dados, durante a triagem dos textos percebemos que os termos dos títulos e as palavras-chaves empregadas pelos autores nem sempre são muito expressivas das temáticas abordadas nas escritas, já que por vezes não são explicitadas ou atingem grau de relevância a ponto de serem considerados palavras-chaves. Dos 46 trabalhos, apenas 17 traziam termos que faziam referência à Teoria Histórico-cultural, como por exemplo: "organização do

\footnotetext{
${ }^{2}$ A sigla inglesa PDF significa Portable Document Format (Formato Portátil de Documento), isto é, um formato de arquivo criado pela empresa Adobe Systems para que qualquer documento seja visualizado, independentemente de qual tenha sido o programa que o originou. 
ensino", "elaboração conceitual”, "Teoria da Atividade", "Atividade Orientadora de Ensino", entre outras.

Assim, nossa análise se deu mais diretamente sobre termos empregados nos resumos dos trabalhos. Optamos por tal estratégia, pois

O resumo permite outras descobertas, se lido e interrogado para além dele mesmo, numa prática de leitura mais "livre", aquela fora dos preceitos previstos pelo autor. Mas, ao mesmo tempo, a leitura de cada resumo é "freada" pelas pistas, indícios deixados nele pelo autor, que conduzem a uma e não outra compreensão de todo e qualquer resumo. (FERREIRA, 2002, p.269).

A leitura e análise dos resumos permitiu identificar a temática dos artigos, conforme quadro abaixo:

Quadro 1. Temática dos artigos

\begin{tabular}{|l|l|}
\hline TEMÁTICA & QUANTIDADE \\
\hline Didática/prática pedagógica & 7 \\
\hline Sentidos/aprendizagens dos alunos & 7 \\
\hline Organização do ensino & 6 \\
\hline Formação de professores & 5 \\
\hline Apropriação/formação de conceitos & 5 \\
\hline Aprendizagem da docência & 4 \\
\hline Interação nas aulas & 4 \\
\hline Políticas de avaliação externa & 3 \\
\hline Modelagem matemática & 2 \\
\hline Desenvolvimento do psiquismo & 1 \\
\hline Atividade Orientadora de Ensino & 1 \\
\hline Teoria da Atividade & 1 \\
\hline Mediação & 1 \\
\hline Tecnologia & 1 \\
\hline
\end{tabular}

Fonte: As autoras.

Ao fazermos uma análise quantitativa sobre os dados contidos na tabela quanto à região do país a que pertencem os autores, foi possível constatar que a maioria dos trabalhos concentrase na região Sudeste (24) - entre São Paulo (22) e Minas Gerais (2) -; seguida da região Sul (13) divididos entre os estados de Rio Grande do Sul (7), Paraná (5) e Santa Catarina (1). Na região Centro-oeste apareceram (7) trabalhos, distribuídos nos estados de Goiás (5), Mato Grosso (1) e Mato Grosso do Sul (1) e, por fim, na região Nordeste (2), concentrados no estado de Pernambuco.

Uma das possíveis causas para a maior produção científica de artigos nas regiões Sudeste e Sul pode ser o grande número de Programas de Pós-Graduação em Educação Matemática e áreas correlatas, de universidades públicas e privadas, nessa localidade.

Quanto ao tipo de estudo, 10 (dez) trabalhos classificam-se como resultado de pesquisas de mestrado, enquanto que apenas três são de doutorado. Do total de 46 trabalhos, 31 não informaram o tipo de estudo, o que nos levou a classificá-los somente como artigos. Por fim, os dois últimos trabalhos referiam-se a minicurso (1) e relato de experiência (1).

Com relação à análise dos conceitos da Teoria Histórico-Cultural abordados nas produções analisadas, destacaram-se: aprendizagem, significado e desenvolvimento.

\section{CONCLUSÃO}

\footnotetext{
${ }^{3}$ A soma dessa coluna ultrapassa onumero de 46 artigos analisados, pois 2 artigos se enquadraram em duas tematicas simultaneamente.
} 
Essa pesquisa de iniciação científica mostrou-se pertinente por propor um levantamento das pesquisas sobre a Teoria Histórico-Cultural e o ensino de Matemática apresentados nos anais do XI ENEM - Encontro Nacional de Educação Matemática, tendo como finalidade de organizar um panorama dos estudos, além de constituir um banco de dados para acesso, organização e pesquisa do material para subsidiar novos estudos sobre a temática.

Contudo é necessário dar continuidade a este estudo de maneira mais minuciosa, de natureza qualitativa, mediante leituras de obras de Lev Semyonovich Vigotski, para assim identificar se os conceitos identificados nos trabalhos, realmente são próprios da Teoria HistóricoCultural.

\section{REFERÊNCIAS}

BOGDAN, Robert. C.; BIKLEN, Sari K. Investigação qualitativa em educação. Porto: Porto Editora, 1994.

Encontro Nacional de Educação Matemática, 2013, Curitiba. Anais do XI Encontro Nacional de Educação Matemática, 2013.

GIL, Antônio Carlos. Como elaborar projetos de pesquisa. São Paulo: Atlas, 2010.

SAVIANI, Dermeval. Educação: do senso comum à consciência filosófica. São Paulo: Cortez, 1985. . Pedagogia histórico-crítica: primeiras aproximações. 2 ed. São Paulo: Cortez: Autores Associados, 1991.

VYGOTSKY, Lev Semenovitch. A formação social da mente. São Paulo: Martins Fontes, 1998. 